\title{
Lithium chloride produces illness-induced analgesia
}

\author{
RAZ YIRMIYA, ISRAEL LIEBLICH, JOHN C. LIEBESKIND, and JOHN GARCIA \\ University of California, Los Angeles, California
}

\begin{abstract}
The analgesic effects of lithium chloride $(\mathrm{LiCl})$ and their interaction with the analgesic effects of morphine were studied in rats. After recording rats' baseline pain sensitivity in the hot-plate test, we injected half the rats with $\mathrm{LiCl}(127 \mathrm{mg} / \mathrm{kg}$ i.p.) and half with saline. A second hot-plate latency measurement was taken 100 min later. Following this measurement, half the LiCl-and half the saline-injected rats were injected with morphine $(10 \mathrm{mg} / \mathrm{kg}$ s.c. $)$, and the others with saline. A third hot-plate latency measurement was taken 20 min later. $\mathrm{LiCl}$ produced strong analgesic effects that were comparable to those produced by morphine. The analgesic effects in the group that received both $\mathrm{LiCl}$ and morphine was approximately equal to the sum of the analgesic effects measured in the groups that received each of these drugs with saline. The results support our hypothesis that drugs that produce gastrointestinal illness and nausea also produce analgesia.
\end{abstract}

A general theory of aversion learning, proposed by Garcia, Lasiter, Bermundez-Rattoni, and Deems (1985), suggests that in the vertebrate brain, two separate defense systems have evolved in response to selection pressures inherent in the food chain. The skin-defense system is used by the animal to protect itself from predatory attack and involves a selective association of exteroceptive stimuli with peripheral insult and pain. The gut-defense system is used to protect the animal from ingested toxins and involves an association between taste and delayed illness and nausea.

Garcia et al. (1985) further suggested that an inhibitory mechanism separates the two systems. This hypothesis was based on the common observation that excitation of external coping mechanisms is accompanied by inhibition of the internal digestive processes. For example, fear or apprehension attenuates feeding, appetite, and gastric motility. Reciprocally, activation of the gut system has an inhibitory effect on the external coping mechanism. For example, a heavy meal often is followed by drowsiness and muscular relaxation. According to Garcia et al.'s theory, an illness-inducing agent that activates the gutdefense system should inhibit the skin-defense system and, therefore, produce analgesia. The present experiment was designed to test this hypothesis by studying the effect of lithium chloride, which is known to induce gastrointestinal illness and nausea, on pain responsiveness. Additionally, these effects were compared with the analgesic ef-

We note with sorrow the death of our colleague and friend, Professor Israel Lieblich, September 25, 1986.

This research was supported by NIH Grants NS 07628 to John C. Liebeskind and NS 11618 to John Garcia and by a gift from the David $\mathrm{H}$. Murdock Foundation for Advanced Brain Studies. Requests for reprints should be sent to Raz Yirmiya, Department of Psychology, University of California, Los Angeles, CA 90024. fects of morphine, and a possible interaction between the two drugs was explored.

\section{METHOD}

\section{Subjects}

The subjects were 33 male Sprague-Dawley rats (Simonson, Gilroy, CA) that weighed 233-288 g. The rats were housed individually in standard stainless steel cages in an animal colony. Testing was done in a different room during the first third of the dark portion of a 12:12-h light:dark cycle.

\section{Procedure}

Pain sensitivity was measured with the hot-plate test. The apparatus consisted of a circular plate platform at the bottom of a clear Plexiglas cylinder $22 \mathrm{~cm}$ in diameter and $30 \mathrm{~cm}$ high. The plate's temperature was maintained at $51.5^{\circ} \mathrm{C}$ by a thermostatically controlled water bath. The rat was placed onto the plate, and the latency to lick the hind paw was recorded. In the absence of this behavior, the rat was taken out after $60 \mathrm{sec}$. A baseline hot-plate latency measurement was taken for each rat, followed immediately by an injection of lithium chloride $(\mathrm{LiCl})$ $(127 \mathrm{mg} / \mathrm{kg})$ in 17 rats and saline in the others. The injections were in a volume of $20 \mathrm{ml} / \mathrm{kg}$ i.p. A second hot-plate measurement was taken 100 min later. Following this test, about half of the $\mathrm{LiCl}$-injected rats (Group LiCl-Mor, $n=8$ ) and half of the saline-injected rats (Group SalMor, $n=8)$ were subcutaneously injected with morphine $(10 \mathrm{mg} / \mathrm{kg}$, dissolved in saline in a volume of $1 \mathrm{ml} / \mathrm{kg}$ ). The other rats received an injection of saline (Group LiCl-Sal, $n=9$; and Group Sal-Sal, $n=8$ ). A final hot-plate measurement was taken 20 min later.

\section{RESULTS}

The latencies ( \pm standard errors of the mean) to lick the hind paw in the hot-plate test are presented in Figure 1. No significant baseline differences were observed among the groups. $\mathrm{LiCl}$ significantly elevated hot-plate latency 100 min after its administration $[t(31)=3.46, p<.05]$. A two-way analysis of variance showed that both $\mathrm{LiCl}$ and morphine significantly elevated hot-plate latency $120 \mathrm{~min}$ after $\mathrm{LiCl}$ administration $[F(1,29)=6.18$, $p<.02$, and $F(1,29)=15.5, p<.001$, respectively]. 


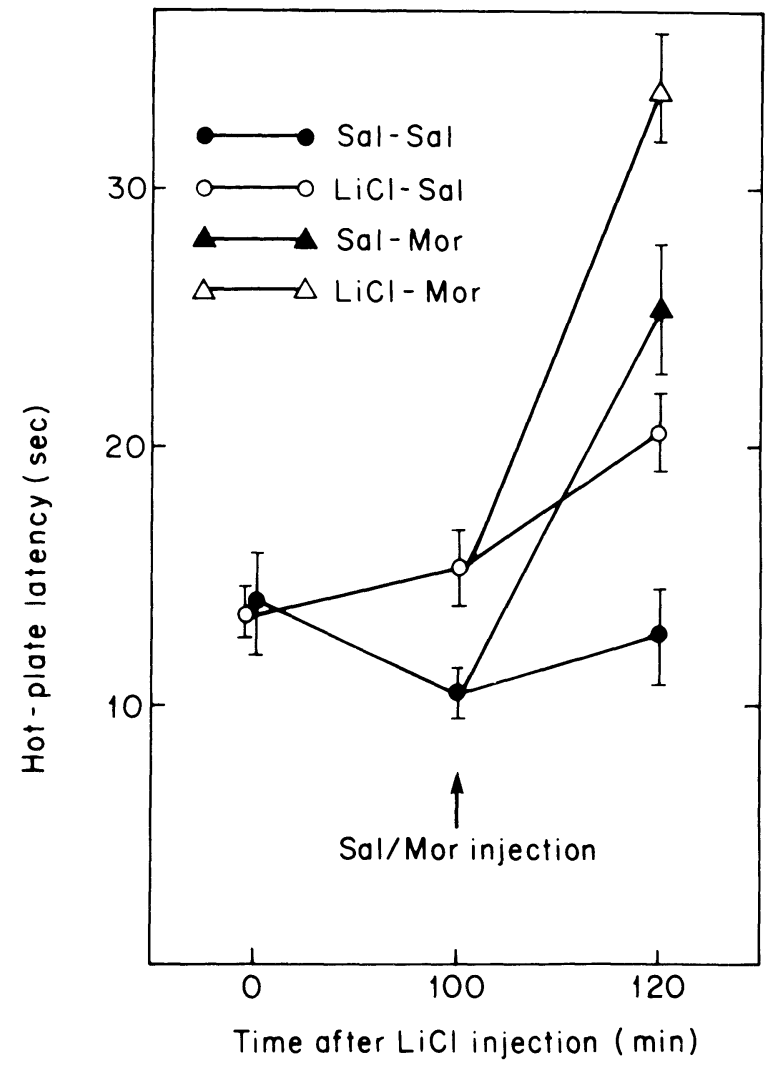

Figure 1. Analgesic effects of lithium chloride ( $\mathrm{LiCl}$ ) and morphine (Mor) in the hot-plate test. Mean hot-plate latencies were recorded immediately before and 100 and $120 \mathrm{~min}$ after an injection of either $\mathrm{LiCl}$ or saline (Sal). A second injection of either morphine or saline was administered to each rat immediately after the second hot-plate latency measurement. Error bars represent standard errors of the mean.

Post-hoc comparisons using the Newman-Keuls test showed no significant difference between the hot-plate latency of Group LiCl-Sal and that of Group Sal-Mor. The hot-plate latency of group LiCl-Mor was significantly higher than that of Group LiCl-Sal $(p<.05)$ and was about equal to the sum of the analgesic effects observed in Groups LiCl-Sal and Sal-Mor.

\section{DISCUSSION}

The results indicate that an injection of a high dose of lithium can produce strong analgesic effects that are comparable to the analgesic effect of a $10-\mathrm{mg} / \mathrm{kg}$ dose of morphine. Additionally, the lithium-induced analgesia can summate with the analgesia produced by morphine. These results support the hypothesis that an illness-inducing agent also produces analgesia. Other illness-inducing agents, such as apomorphine (Paalzow \& Paalzow, 1975; Vedernikov, 1969) and centrifugal rotation (Hayes, Bennett, Newlon, \& Mayer, 1978), have also been found to produce analgesia, giving further support to this hypothesis. Morphine has been shown to produce gastrointestinal illness and can support tasteaversion learning (LeBlanc \& Cappell, 1975). Thus, it is possible that some of morphine's analgesic action and its enhanced effect when given with lithium result from its illness-inducing properties.
Studies of the interaction of lithium with morphine have yielded inconsistent and contradictory results. Several studies found that lithium administration increases the analgesic properties of morphine (Jensen, 1974; Tulunay, Kiran, \& Kaymakcalan, 1971), whereas others found no such interaction (Saarnivaara \& Mannisto, 1976). The results of the present experiment confirm previous demonstrations of the enhancement of morphine analgesia by lithium. It may be suggested that the use of different species (e.g., mice vs. rats), drug administration parameters (e.g., acute vs. chronic), or analgesia tests (e.g., hot-plate vs. tail-flick tests) accounts for these conflicting findings.

Previous studies of the effects of lithium on responsiveness to painful stimulation have also yielded inconsistent and sometimes contradictory results. In some studies, for example, both acute (Tulunay et al., 1971) and chronic (Amir \& Simantov, 1981) administration of lithium produced analgesia in animals, whereas in others, either no analgesia (Jensen, 1974; Mannisto \& Saarnivaara, 1976) or heightened sensitivity to painful stimulation (Harrison-Read \& Steinberg, 1971) has been reported. The results of the present study are in agreement with previous studies showing lithium-induced analgesia in animals. The failure of other studies to find this effect may also have resulted from use of different species, lower doses of lithium, or the different analgesic test used. For example, several studies that did not find lithium-induced analgesia used lower doses than the one used in the present experiment, and thus might have induced less or no illness. Further research is needed to assess the relations between the magnitude of the illness and the analgesia it produces.

\section{REFERENCES}

Amir, S., \& Simantov, R. (1981). Chronic lithium administration alters the interaction between opiate antagonists and opiate receptors in vivo. Neuropharmacology, 20, 587-591.

Garcia, J., Lasiter, P. S., Bermundez-Rattoni, F., \& Deems, D. A. (1985). A general theory of aversion learning. Annals of the New York Academy of Sciences, 443, 8-21.

Harrison-Read, P. E., \& STEINBerg, H. (1971). Lithium-induced hypersensitivity to foot shock in rats and the role of 5hydroxytryptophan. Nature New Biology, 232, 120-121.

Hayes, R. L., Bennett, G. J., Newlon, P. G., \& Mayer, D. J. (1978). Behavioral and physiological studies of non-narcotic analgesia in the rat elicited by certain environmental stimuli. Brain Research, 155, 69-90.

JENSEN, J. (1974). The effect of prolonged lithium ingestion on morphine actions in the rat. Acta Pharmacologica et Toxicologica, 35, $395-401$.

LeBlanc, A. E., \& Cappell, H. (1975). Antagonism of morphineinduced aversive conditioning by naloxone. Pharmacology, Biochemistry \& Behavior, 3, 185-188.

Mannisto, P. T., \& SaARnivaARA, L. (1976). Effects of lithium and rubidium on the antinociception and behavior in mice: II. Studies on three tricyclic antidepressants and pimozide. Archives Internationales de Pharmacodynamie et de Therapie, 222, 293-299.

PaAlzow, G., \& PaAlzow, L. (1975). Enhancement of apomorphineinduced inhibition of vocalization after discharge response by theophylline. Life Sciences, 17, 1145-1151.

SaARnivaAra, L., \& Mannisto, P. T. (1976). Effects of lithium and rubidium on antinociception and behavior in mice: I. Studies on narcotic analgesics and antagonists. Archives Internationales de Pharmacodynamie et de Therapie, 222, 282-292.

Tulunay, F. C., Kiran, B. K., \& Kaymakcalan, S. (1971). Interaction between morphine and lithium. Acta Medica Turcica, 8, 51-60.

VEDERNIKOV, Y. D. (1969). Interaction of amphetamine, apomorphine, disulfiram with morphine and the role played by catacholamines in morphine analgesic action. Archives International Pharmacodynamics, $182,59-64$

(Manuscript received for publication September 16, 1987.) 